\title{
Guidelines and reality in studies on the economic costs of alcohol use: a systematic review
}

\author{
Sinclair Carr ${ }^{1}$, Jürgen Rehm ${ }^{2,3,4,5,6,7}$, and Jakob Manthey ${ }^{1,2,8}$ \\ ${ }^{1}$ Centre for Interdisciplinary Addiction Research, Department of Psychiatry, University Medical Center Hamburg-Eppendorf, Hamburg, \\ Germany \\ ${ }^{2}$ Institute of Clinical Psychology and Psychotherapy, Technische Universität Dresden, Dresden, Germany \\ ${ }^{3}$ Institute for Mental Health Policy Research and Campbell Family Mental Health Institute, Centre for Addiction and Mental Health, Toronto, \\ Ontario, Canada \\ ${ }^{4}$ Dalla Lana School of Public Health, University of Toronto, Toronto, Ontario, Canada \\ ${ }^{5}$ Institute of Medical Science, University of Toronto, Toronto, Ontario, Canada \\ ${ }^{6}$ Department of Psychiatry, University of Toronto, Toronto, Ontario, Canada \\ ${ }^{7}$ Department of International Health Projects, Institute for Leadership and Health Management, I.M. Sechenov First Moscow State \\ Medical University, Moscow, Russian Federation \\ ${ }^{8}$ Department of Psychiatry, Medical Faculty, University of Leipzig, Leipzig, Germany
}

\begin{abstract}
Aim: To identify guidelines for estimating alcohol-attributable cost of illness (COI) and actual COI studies, and to assess to what extent core recommendations have been implemented.

Design: The systematic review was conducted in February 2019 according to the PRISMA statement. Relevant COI guidelines and actual alcohol COI studies published since 2009 (when the last systematic review was published) were identified by searching databases MEDLINE and EMBASE, as well as literature known by the authors.
\end{abstract}

Measures: Standards and recommendations of published COI guidelines, and actual COI studies estimating the total costs of alcohol.

Findings: Fourteen guidelines and eighteen COI studies were identified, and relevant indicators were extracted. Large discrepancies between recommended and implemented methods were determined. Contrary to most current guidelines, which were barely acknowledged at all, (a) predefined direct and indirect cost groups were only partially included, (b) estimates were compared with GDP in only about half of the studies, and (c) avoidable costs - a complementary concept to the more common scenario of complete alcohol abstinence - were never estimated.

Conclusions: Adherence to guidelines in published COI studies is low. We propose content-related and software-based solutions to adopting a common standard, which could reduce heterogeneity and enhance comparability in alcohol COI studies.

\section{Introduction}

Alcohol consumption has been identified as a leading risk factor for disease burden globally (Rehm \& Imtiaz, 2016; Stanaway et al., 2018) and was accountable for about $5 \%$ of all deaths in 2016 (Shield et al., 2020). In more recent decades, consumption has increased overall and is projected to further increase in the current decade (Manthey et al., 2019); on the other hand, the World Health Organization (WHO) has set a target to reduce alcohol consumption by $10 \%$ by 2025 (World Health Organization, 2010).
To promote effective policy responses for reducing alcohol use, the burden of disease metrics, such as mortality and morbidity, is often cited. Chisholm and colleagues (2018) discuss the three most cost-effective interventions. More inclusive, and perhaps more relevant to policymakers are cost of Illness (COI) studies that summarize the societal burden from a given disease, including health and other relevant indicators. Initially, COI studies were proposed for diseases such as the nervous, circulatory, respiratory, and digestive systems, as well as for other disorders (Rice, 1967), but were later extended to risk factors as well. A 2009 review of COI studies found that $2-2.5 \%$ of the national gross

\footnotetext{
Correspondence: Jakob Manthey; Institute of Clinical Psychology and Psychotherapy, Technische Universität Dresden, Chemnitzer Str. 46, 01187 Dresden, Germany; e-mail: jakob.manthey@tu-dresden.de

Financial support: Federal Ministry of Health in Germany (funding \#: ZMVI1-2518DSM210); Open Access Funding by the Publication Fund of the TU Dresden Declaration of interest: None

Keywords: Alcohol, Cost of illness, Guidelines, Methodology, Economic costs
} 
domestic product was attributable to alcohol use in middleand high-income countries (Rehm et al., 2009).

Estimating the attributable COI for alcohol and other substances is not as straightforward as for example, for cardiovascular diseases, because alcohol consumption impacts not only the drinkers' health, but also their productivity, driving performance, the likelihood of encountering legal problems, as well as harm caused to others. Furthermore, a large part of the attributable burden is not caused by persons with an identifiable diagnosis, such as alcohol use disorders, but rather by the larger number of drinkers with moderate or hazardous drinking levels (Rehm, Shield, Gmel, Rehm, \& Frick, 2013). This pattern can be explained by the elevated risk associated with low amounts of alcohol intake for some diseases such as certain cancer types and hypertension. Shield and colleagues (2020) summarize respective risk functions in their appendix; for an example with breast cancer, see Shield, Soerjomataram, and Rehm (2016). Consequently, any alcohol COI study should aim to estimate the attributable costs of any alcohol consumption, rather than for selected groups of drinkers only.

In order to standardize the assessment of attributable costs, and to ensure that all relevant cost categories are considered, substance-specific guidelines have been proposed (Single et al., 2003).

However, it was previously unclear whether all of these recommendations had actually been implemented in the estimation of alcohol-attributable social costs. According to the review cited above, health care costs only constituted $13 \%$ of costs in high-income countries, illustrating the need to include all relevant cost drivers to improve the comparability and plausibility of COI studies for policymakers.

This study sought to (a) identify relevant guidelines for estimating alcohol-attributable COI and actual COI studies for alcohol, (b) compare core recommendations to studies that actually estimated the social costs arising from alcohol consumption, and (c) summarize other recommendations for COI studies, with focus on top-down and bottom-up approach.

\section{Method}

\section{Search Strategy}

A systematic review was conducted to identify literature relevant to implementing alcohol COI studies (PROSPERO register number CRD42020139594). The review consisted of two separate parts: firstly, recommendations of published COI guidelines and standards; and secondly, actual COI studies published since 2009, the year when the last systematic review was published (Rehm et al., 2009). The process of selecting, reviewing, and analyzing literature was conducted in February 2019, and further updated in July 2020, and is described in the following (see Table A1 in the appendix for the exact search strategy).
The PRISMA flow chart shows the process of systematically identifying, selecting, and reviewing literature with regard to identifying COI studies, and the respective published guidelines (Figure 1). In the first step, 3,911 records were identified from literature databases (EMBASE and MEDLINE) that could be included as possible literature. A further 17 records, which were either previously known or had been identified by experts, were also included. More than a third of all the records $(n=1,481)$ were excluded, because they were either duplicates of already identified studies, or COI studies published before 2009. Of the remaining records, 136 were included in a more intensive analysis (full-text screening). Eighteen full-text records were subsequently selected. The other records $(n=118)$ were excluded, for the following reasons: 65 calculated costs of alcohol restricted to a selected population of drinkers (e.g., with alcohol dependence); some were published as a comment or review; no costs of alcohol were reported; missing information; falsely reported results; duplicate reporting of the same study; incompatible language (one study was published in Korean (Kim, Chung, Lee, \& Park, 2010)); and one paper was not accessible. Ultimately, 18 COI studies and 14 guidelines were included in the final analysis.

\section{What Are Recommendations to Conduct COI Studies for Alcohol?}

Recommendations and guidelines for the conception and methodology of COI studies were identified through references in the $18 \mathrm{COI}$ studies. Those studies either applied the guidelines or referred to them as part of their theoretical backgrounds. The 14 published guidelines were classified as to how they contributed to the design and implementation of COI studies. Only recommendations for COI calculations at a national level were included, as this review was conducted within a larger project funded by the Federal Ministry of Health in Germany, which aimed to conceptualize a COI study for alcohol use in Germany. Although many of the guidelines do not specifically refer to alcohol COI, but rather to $\mathrm{COI}$ in general, they were nevertheless included due to their relevance in the implementation of cost estimations attributable to alcohol consumption.

We derived two sets of recommendations from the guidelines: core recommendations, which we then compared with actual COI studies for alcohol; and recommendations for other aspects that were primarily relevant to the use of the top-down and bottom-up approaches.

\section{Which Cost Categories Were Estimated in COI Studies for Alcohol?}

For each COI study, six categories were identified: descriptive information of the COI study, estimation of direct, indirect, intangible, and saved costs, as well as other aspects such as comparison indicators, or referenced COI studies (further details in Table B1 in the appendix). The main interest was to classify costs induced by alcohol consumption in the respective cost groups and their subgroups. 
Figure 1

PRISMA Diagram (According to Moher, Liberati, Tetzlaff, \& Altman (2009))

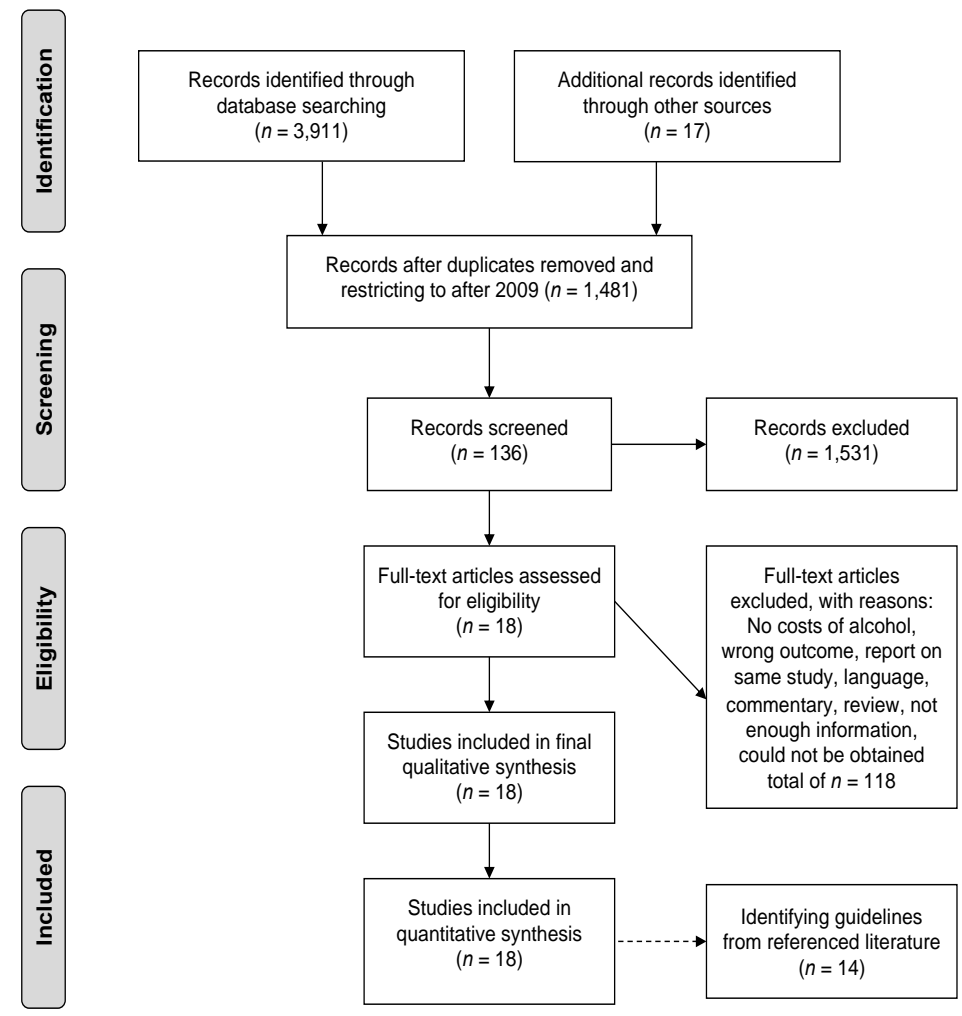

The approach to estimate costs was classified as either a topdown method, a bottom-up method, or a mixture of both. The former divides the overall costs of a category (such as all hospitalizations) by a population-attributable fraction (PAF), which gives the costs attributable to alcohol consumption. The latter estimates the costs of alcohol through data from registers or surveys.

Cost estimates from COI studies are often compared to macroeconomic indicators such as gross domestic product (GDP) or gross national income (GNI). Studies were classified according to whether they used a comparative indicator, and the indicator to which comparisons were made.

\section{Results}

\section{Aim 1: Core Recommendations to Conduct COI Studies for Alcohol.}

Within the systematic literature review, the following 14 guidelines and standards for COI studies at national level were identified (see Table 1).

Rice $(1966,1967)$ was the first to conceptualize the COI methodology, which was later applied to substance abuse studies (Rice, Kelman, \& Miller, 1991; Rice, Kelman, Miller, \& Dunmeyer, 1990). Hodgson and Meiners (1982) updated Rice (1966, 1967) guidelines, in particular discussing the measurements and methods of estimation of relevant cost factors (Hodgson \& Meiners, 1982). More recently, several cost groups such as criminality, traffic accidents, or fire damage, were recommended for inclusion in alcohol COI studies. However, even though guidelines were published, and relevant additional factors added, principal criticism of those COI studies, which appeared soon after Rice and colleagues $(1990,1991)$ publications, remained (Byford, Torgerson, \& Raftery, 2000; Drummond, 1992). As a result of limited clarity on methodological implementations, Single and colleagues developed international guidelines for alcohol cost studies in 1996 (Single et al., 1996), which were updated in 2003 (Single et al., 2003), and applied in a comprehensive Canadian cost study for substance abuse in 2006 (Rehm et al., 2006). However, the results of COI studies still largely differed methodologically and analytically, which led to further criticism - see reviews from Rehm and colleagues (2009) and Thavorncharoensap, Teerawattananon, Yothasamut, Lertpitakpong, and Chaikledkaew (2009).

In 2010, Møller and Matic published a detailed WHO guideline with recommendations and standards for future 
COI studies of alcohol consumption, with direct responses to specific criticisms (Møller \& Matic, 2010). They also referred to guidelines concerning avoidable costs, which were developed and applied in economic (Collins et al., 2006) and epidemiologic studies (Murray, Ezzati, Lopez, Rodgers, \& Vander Hoorn, 2003; Rehm, Taylor, Patra, \& Gmel, 2006; Jarl, Gerdtham, Ludbrook, \& Petrie, 2010). In their guideline, they concentrated on three main criticisms of COI methodologies. Firstly, there is no standardized comparability in COI studies, which results in large differences in applied methods, with results being hardly comparable. Many studies only included cost groups with high economic impact, such as health care and work-related costs, without estimating other categories, either due to missing data, or their not being quantifiable. Møller and Matic (2010) recommended including all predefined cost categories (direct and indirect costs with respective subgroups, see Figure 2), which were classified by Single and colleagues (2003). Secondly, comparing cost estimates to GDP or other macroeconomic indicators is invalid and considered a violation of economic assumptions, because cost estimates are not driven solely by those categories which are also included in the calculation of GDP. In their guidelines, they recommend avoiding such comparisons. Thirdly, COI studies fall short of influencing policy considerations because their counterfactual scenarios are unfeasible. In terms of alcohol consumption, the counterfactual scenario of total abstinence is unsuited for policy decisions, because it is either impossible to implement, or highly undesirable in a large majority of countries (Mäkelä, 2012). The WHO guidelines recommend complementing such scenarios with the concept of avoidable costs. Additionally, Møller and Matic (2010) specified frameworks for avoidable costs in order to facilitate reliable calculations and enable influencing alcohol (control) policy.

Quinet (2014) discussed the methodology of assessing public investments, which allows the estimation of the effect of alcohol use on the state budget. In the most recent review, guidelines for the estimation of social costs attributable to illegal drugs were analyzed, and theoretical aspects and definitions were discussed, which could enable the definition of standards for this type of COI studies (Alberto Vella, García-Altes, Segura García, Ibáñez Martínez, \& Colom Farran, 2018).

Furthermore, other health-economic study designs referring to alcohol consumption exist, such as the traditional approach of a comparative analysis of governmental health care expenditures (Murray, Govindaraj, \& Musgrove, 1994). However, this method has different objectives, and treats risk factors like alcohol consumption inadequately.

\section{Estimated Cost Categories in COI Studies for Alcohol}

Eighteen COI studies aimed to estimate the overall costs of alcohol, including the relevant costs for region and/or country. In the following, previously defined indicators of those studies are described (see Table 2 for estimated cost categories, and Table $\mathrm{C} 1$ in the appendix for a detailed listing of all extracted components).
Table 1

Guidelines and standards for COI studies relevant for estimating the costs of alcohol use

\begin{tabular}{|c|c|}
\hline Author(s) & Title \\
\hline $\begin{array}{l}\text { Byford et al., } \\
2000\end{array}$ & Economic note: Cost of illness studies \\
\hline $\begin{array}{l}\text { Collins et al. } \\
(2006)\end{array}$ & $\begin{array}{l}\text { International guidelines for the estimation } \\
\text { of the avoidable costs of substance abuse }\end{array}$ \\
\hline $\begin{array}{l}\text { Drummond } \\
(1992)\end{array}$ & Cost-of-illness studies: A major headache? \\
\hline $\begin{array}{l}\text { Hodgson and } \\
\text { Meiners (1982) }\end{array}$ & $\begin{array}{l}\text { Cost-of-illness methodology: A guide to } \\
\text { current practices and procedures }\end{array}$ \\
\hline Jarl et al. (2010) & $\begin{array}{l}\text { On measurement of avoidable and } \\
\text { unavoidable cost of alcohol: An application } \\
\text { of method for estimating costs due to prior } \\
\text { consumption }\end{array}$ \\
\hline $\begin{array}{l}\text { Møller and } \\
\text { Matic (2010) }\end{array}$ & $\begin{array}{l}\text { Best practice in estimating the costs of } \\
\text { alcohol - Recommendations for future } \\
\text { studies }\end{array}$ \\
\hline $\begin{array}{l}\text { Murray et al. } \\
\text { (1994) }\end{array}$ & $\begin{array}{l}\text { National health expenditures: A global } \\
\text { analysis }\end{array}$ \\
\hline Quinet (2014) & $\begin{array}{l}\text { L'évaluation socioéconomique des } \\
\text { investissements publics }\end{array}$ \\
\hline $\begin{array}{l}\text { Rehm et al. } \\
\text { (2006) }\end{array}$ & $\begin{array}{l}\text { Avoidable burden of disease: Conceptual } \\
\text { and methodological issues in substance } \\
\text { abuse epidemiology }\end{array}$ \\
\hline Rice (1966) & Estimating the cost of illness \\
\hline Rice (1967) & Estimating the cost of illness \\
\hline $\begin{array}{l}\text { Single et al. } \\
(1996)\end{array}$ & $\begin{array}{l}\text { International Guidelines for Estimating the } \\
\text { Costs of Substance Abuse }\end{array}$ \\
\hline $\begin{array}{l}\text { Single et al. } \\
(2003)\end{array}$ & $\begin{array}{l}\text { International guidelines for estimating the } \\
\text { costs of substance abuse, } 2 \text { nd edition }\end{array}$ \\
\hline $\begin{array}{l}\text { Alberto Vella et } \\
\text { al. (2018) }\end{array}$ & $\begin{array}{l}\text { Systematic review of guidelines in } \\
\text { estimating social costs on drugs }\end{array}$ \\
\hline
\end{tabular}

All studies calculated direct costs of alcohol consumption, including specific health care costs. Alcohol-associated criminality was included in 14 studies, whereas direct cost group estimations were occasionally calculated, such as alcohol-induced traffic crashes $(n=5)$, social work $(n=2)$, and other costs in four studies (e.g., fire-fighting or special education for children with fetal alcohol syndrome).

All COI studies included indirect cost groups. Premature mortality was estimated in almost all studies $(n=16)$. Workplace-related costs were calculated as both absenteeism $(n=13)$ and presenteeism $(n=5)$. Four studies estimated early retirement and two studies unemployment due to alcohol consumption. Restricted activity in household/leisure $(n=4)$, and other indirect costs $(n=7)$ were also considered in alcohol cost estimations. For indirect costs only, the specific approach to estimate productivity losses was identified for each study. The human capital approach (HCA) is used to estimate costs for the society, induced by the alcohol-attributable inability of employees to work. In contrast, the friction cost approach (FCA) takes the employer's perspective when calculating costs, for example the loss of employees, and the subsequent employee replacement costs (Koopmanschap, Rutten, van Ineveld, \& van Roijen, 1995). The human capital approach was applied 
in 15 studies, while one study applied both HCA and FCA. Two studies also applied the value of statistical life approach for calculations, which describes the amount of money people are willing to pay in order to reduce their risk of mortality (Jones-Lee, 1992) and is similar to the willingnessto-pay approach (Hodgson \& Meiners, 1982). In two COI studies, information regarding the estimation methods was not available, though this should not influence the main results of this review.

Intangible costs and saved costs were included in five and four studies, respectively.

\section{Figure 2}

Direct and indirect cost groups of published guidelines (Single et al., 1996)

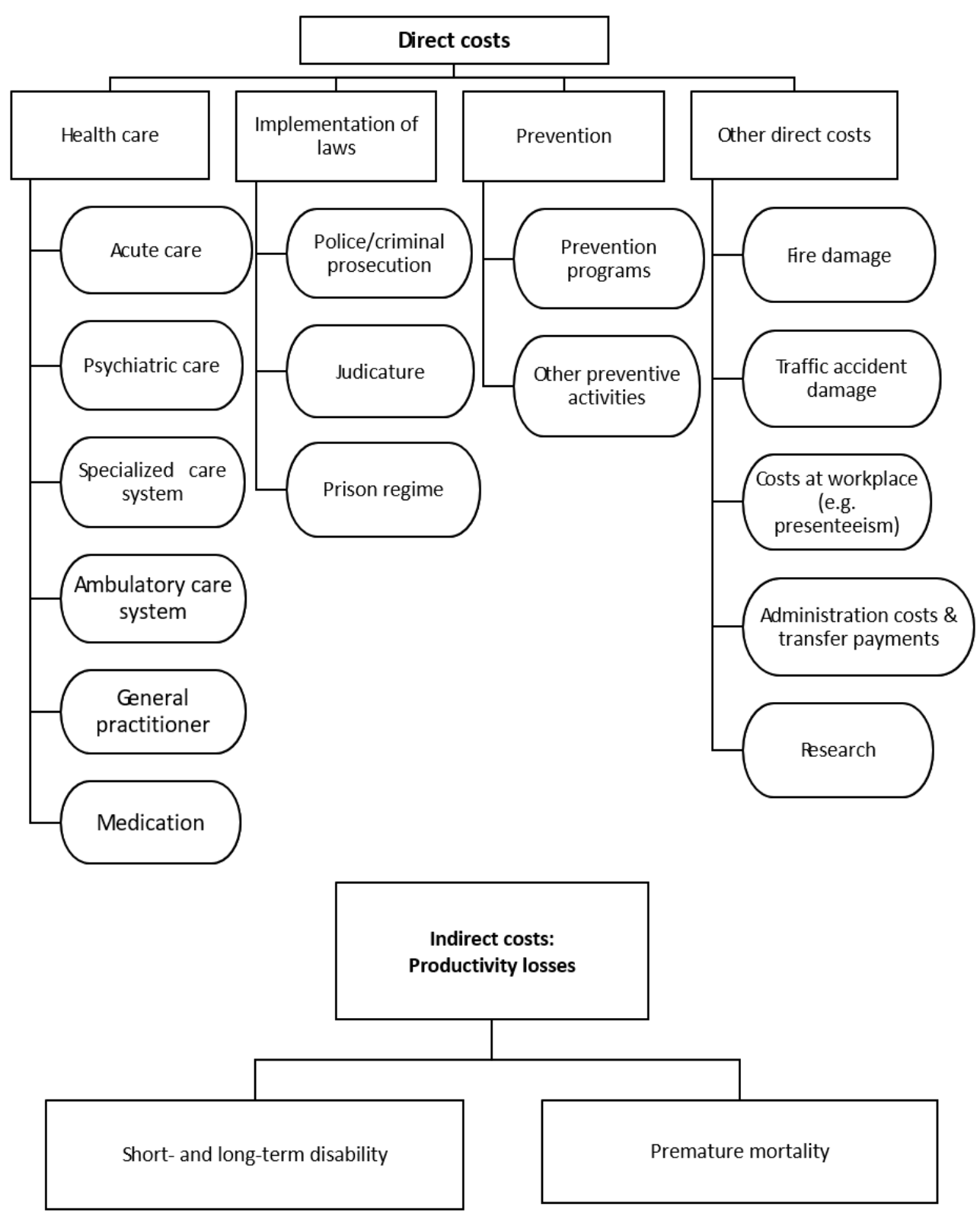


Table 2

Estimated cost categories in alcohol COI studies

\begin{tabular}{|c|c|c|c|c|c|c|c|c|c|c|c|c|c|c|}
\hline \multirow[t]{2}{*}{ Author(s) } & \multicolumn{5}{|c|}{ Direct costs } & \multicolumn{7}{|c|}{ Indirect costs } & \multirow{2}{*}{$\begin{array}{l}\text { Intangible } \\
\text { costs }\end{array}$} & \multirow{2}{*}{$\begin{array}{l}\text { Saved } \\
\text { costs }\end{array}$} \\
\hline & $\begin{array}{c}\text { Health } \\
\text { care }\end{array}$ & Crime & Traffic & $\begin{array}{c}\text { Social } \\
\text { work }\end{array}$ & Other & $\begin{array}{c}\text { Premature } \\
\text { mortality }\end{array}$ & Absenteeism & Presenteeism & $\begin{array}{c}\text { Early } \\
\text { retirement }\end{array}$ & $\begin{array}{c}\text { Restricted } \\
\text { activity* }\end{array}$ & Unemployment & Other & & \\
\hline $\begin{array}{l}\text { Adams and Effertz } \\
\text { (2010) }\end{array}$ & $\mathrm{X}$ & $X$ & $X$ & - & - & $\mathrm{X}(\mathrm{HCA})$ & $\mathrm{X}(\mathrm{HCA})$ & - & $\mathrm{X}(\mathrm{HCA})$ & - & - & $\mathrm{x}(\mathrm{HCA})$ & - & - \\
\hline Barkey (2009) & $\mathrm{X}$ & $\mathrm{X}$ & - & - & - & $\mathrm{X}(\mathrm{HCA})$ & $\mathrm{X}(\mathrm{HCA})$ & $\mathrm{X}(\mathrm{HCA})$ & $\mathrm{X}(\mathrm{HCA})$ & - & - & - & - & - \\
\hline $\begin{array}{l}\text { Beale, Sanderson, } \\
\text { Kruger, Glanville, \& } \\
\text { Duffy (2010) }\end{array}$ & $\mathrm{X}$ & $X$ & - & $\mathrm{X}$ & - & X (HCA) & X (HCA) & X (HCA) & X (HCA) & - & X (HCA) & - & - & $\mathrm{X}$ \\
\hline Bohs \& Sayed (2009) & $\mathrm{X}$ & $\mathrm{X}$ & $\mathrm{X}$ & - & - & - & $\mathrm{X}(\mathrm{HCA})$ & - & - & - & - & $\begin{array}{l}\text { X (HCA; } \\
\text { VSL) }\end{array}$ & - & - \\
\hline $\begin{array}{l}\text { Department of Health } \\
\text { Social Services \& } \\
\text { Public Safety (2010) }\end{array}$ & $\mathrm{X}$ & $X$ & - & $\mathrm{X}$ & - & X (HCA) & X (HCA) & X (HCA) & - & - & X (HCA) & - & - & - \\
\hline $\begin{array}{l}\text { Ivano Scandurra, } \\
\text { Garcia-Altes, \& } \\
\text { Nebot (2011) } \\
\text { Jyani, Prinja, }\end{array}$ & $\mathrm{X}$ & - & - & - & - & X (HCA) & X (HCA) & - & - & - & - & - & - & - \\
\hline $\begin{array}{l}\text { Ambekar, Bahuguna, } \\
\& \text { Kumar (2019) }\end{array}$ & $\mathrm{x}$ & - & - & - & - & $\mathrm{X}(\mathrm{HCA})$ & $\mathrm{X}(\mathrm{HCA})$ & - & - & - & - & - & - & - \\
\hline $\begin{array}{l}\text { Kopp \& Ogrodnik } \\
\text { (2017) }\end{array}$ & $\mathrm{X}$ & $\mathrm{X}$ & - & - & - & $\mathrm{X}(\mathrm{HCA})$ & - & - & - & - & - & - & $\mathrm{X}$ & $\mathrm{X}$ \\
\hline Lievens et al. (2017) & $\mathrm{X}$ & $\mathrm{X}$ & - & - & - & $\mathrm{X}(\mathrm{HCA})$ & - & - & $\mathrm{X}(\mathrm{HCA})$ & - & - & $\mathrm{X}(\mathrm{HCA})$ & $\mathrm{X}$ & - \\
\hline $\begin{array}{l}\text { Manning, Smith, and } \\
\text { Mazerolle (2013) }\end{array}$ & $\mathrm{x}$ & $\mathrm{x}$ & $\mathrm{x}$ & - & - & $\mathrm{X}$ (missing) & $\mathrm{X}$ (missing) & - & - & $\mathrm{X}$ (missing) & - & - & - & - \\
\hline $\begin{array}{l}\text { Matzopoulos, Truen, } \\
\text { Bowman, \& Corrigall } \\
\text { (2014) }\end{array}$ & $\mathrm{X}$ & $\mathrm{X}$ & - & - & $\mathrm{X}$ & $\begin{array}{l}\text { X (HCA; } \\
\text { VSL) }\end{array}$ & $\mathrm{X}(\mathrm{FCA})$ & - & - & - & - & - & $\mathrm{X}$ & - \\
\hline $\begin{array}{l}\text { Miller et al. (2017) } \\
\text { Paileeklee, Kanato, }\end{array}$ & $\mathrm{X}$ & $\mathrm{X}$ & $\mathrm{X}$ & - & $\mathrm{X}$ & $\mathrm{X}$ (missing) & $\mathrm{X}$ (missing) & - & - & $\mathrm{X}$ (missing) & - & $\mathrm{X}$ (missing) & $\mathrm{X}$ & $\mathrm{X}$ \\
\hline $\begin{array}{l}\text { Kaenmanee, \& } \\
\text { McGhee (2010) }\end{array}$ & $\mathrm{x}$ & $\mathrm{x}$ & - & - & $\mathrm{x}$ & - & - & - & - & $\mathrm{X}(\mathrm{HCA})$ & - & - & - & - \\
\hline $\begin{array}{l}\text { Ranaweera et al. } \\
\text { (2018) }\end{array}$ & $\mathrm{x}$ & - & - & - & - & $\mathrm{X}$ (HCA) & $\mathrm{X}$ (HCA) & - & - & - & - & - & - & - \\
\hline Saar (2009) & $\mathrm{x}$ & $\mathrm{x}$ & $\mathrm{x}$ & - & - & $\mathrm{X}(\mathrm{HCA})$ & $\mathrm{X}(\mathrm{HCA})$ & $\mathrm{X}(\mathrm{HCA})$ & - & - & - & $\mathrm{X}(\mathrm{HCA})$ & - & $\mathrm{x}$ \\
\hline $\begin{array}{l}\text { Thavorncharoensap et } \\
\text { al. (2010) }\end{array}$ & $\mathrm{X}$ & $\mathrm{X}$ & - & - & - & $\mathrm{X}$ (HCA) & $\mathrm{X}$ (HCA) & $\mathrm{X}(\mathrm{HCA})$ & - & - & - & - & - & - \\
\hline $\begin{array}{l}\text { Verhaeghe, Lievens, } \\
\text { Annemans, Vander } \\
\text { Laenen, \& Putman } \\
\text { (2017) }\end{array}$ & $\mathrm{X}$ & - & - & - & - & $\mathrm{X}(\mathrm{HCA})$ & - & - & - & - & - & $\mathrm{X}$ (HCA) & $\mathrm{X}$ & - \\
\hline Wickizer (2013) & $\mathrm{X}$ & $\mathrm{X}$ & - & - & $\mathrm{X}$ & $\mathrm{X}(\mathrm{HCA})$ & - & - & - & $\mathrm{X}(\mathrm{HCA})$ & - & $\mathrm{X}(\mathrm{HCA})$ & - & - \\
\hline Count & 18 & 14 & 5 & 2 & 4 & 16 & 13 & 5 & 4 & 4 & 2 & 7 & 5 & 4 \\
\hline
\end{tabular}

Note. $\mathrm{FCA}=$ friction cost approach, $\mathrm{HCA}=$ human capital approach, $\mathrm{VSL}=$ value of statistical life approach, $\mathrm{X}=$ cost category was estimated.

* in household/leisure 


\section{Aim 2: Comparison of Guidelines and Standards with Actual Implementation.}

A comparison between existing recommendations, especially suggestions to account for common criticisms, and methods employed by COI studies published since 2009, revealed large discrepancies. All COI studies included direct costs, in all cases health care, while crime costs were calculated in 14 studies. In general, other direct cost groups were seldom included: traffic accidents $(n=5)$, social work $(n=2)$, and other costs such as firefighting, or costs of special education for children with fetal alcohol syndrome ( $n$ $=4)$. Indirect costs of alcohol consumption were calculated in all 18 studies: mostly premature mortality $(n=16)$, along with absenteeism $(n=13)$. Five studies estimated costs of presenteeism, and early retirement was calculated in four studies. Restricted activity in household/leisure and unemployment were included in four and two studies, respectively. Seven studies also captured other indirect costs, such as costs through incarcerations, or fetal alcohol syndrome. Møller and Matic (2010) also recommended avoiding comparisons of total cost estimations with GDP, which were implemented in eight of the studies. In terms of using counterfactual scenarios, no study presented avoidable costs.

\section{Aim 3: Other Recommendations for Alcohol COI Studies.}

The identified guidelines also provided recommendations for other aspects when estimating the costs of alcohol consumption. In the following, a summary of recommendations for both the top-down and bottom-up approach is provided. Lastly, recommendations for discounting future costs required for the application of the HCA are summarized.

For the top-down approach, it is necessary to decide which health conditions to include and thus which risk attributions to use to calculate PAFs. This is particularly important because alcohol consumption at low levels is protective for some diseases, such as coronary heart disease. Although international classifications, such as the International Classification of Diseases (ICD), define diseases that are $100 \%$ or partly attributable to alcohol consumption, Single and colleagues (2003) recommend reviewing the most recent studies of causal associations between alcohol consumption and health conditions to obtain appropriate risk attributions, as these vary across societies/countries; this leads to a list of health conditions for the country for which costs are estimated. If specific risk attributions are not available for the respective country, data from similar countries should be imported, and estimates using these should be presented separately (Møller \& Matic, 2010).

On the question of what prevalence data on alcohol consumption should be used, it is recommended that data be obtained from national censuses, surveys, or special population studies (Single et al., 2003). However, no recommendations were made as to which specific drinking categories to use.
For COI studies using a bottom-up approach, only Møller and Matic (2010) gave recommendations, and only for certain cost components, such as health and crime costs, that can also be estimated by the top-down approach. Thus, other potential issues related to the bottom-up approach, such as missing data, or data representativeness, remain unaddressed in guidelines.

The application of HCA, with which future costs of a death can be estimated, requires so-called discounting: as the monetary value declines over time, it is necessary to discount future costs to estimate their value in the present using a discount rate. While Single and colleagues (2003) recommend the use of a comparable rate in all COI studies (5-10\%), Møller and Matic (2010) criticize this approach, because even small differences in discount rates account for large differences in cost estimates. Therefore, instead of applying discount rates for main and sensitivity analyses separately according to the underlying assumptions, they recommend the following: results should be presented in "most likely," "plausible but conservative," and "plausible" scenarios; for each scenario, any assumptions regarding discount rates that are likely to have a moderate impact on results should be included.

\section{Discussion}

The results of this systematic review point to two quite separate worlds: on the one hand, guidelines and the critical discussion of COI methodology and their assumptions, and on the other hand, the actual COI studies (i.e., the estimation of economic costs caused by alcohol use in a certain jurisdiction). The latter have largely ignored methodological suggestions and guidelines of the past decades, except to some degree the earliest guideline of Single and colleagues (1996), but to a greater degree by what data sources were available in the respective countries or jurisdictions. COI studies for alcohol consumption are characterized by high heterogeneity in methodology, as shown by the lack of implementation of core recommendations, which subsequently leads to low comparability between countries. One of the main objectives of such studies, their use for monitoring and benchmarking with other jurisdictions, has not been achieved to date.

Since alcohol use can generate costs in several ways, which all need to be considered when estimating alcoholattributable costs, it is surprising that intangible costs were rarely considered in guidelines and COI studies. Single and colleagues (2003) mentioned two possible reasons for this. On the one hand, measuring intangible as opposed to tangible costs is not trivial, since relevant data is often unavailable - for example, estimating intangible costs using the willingness-to-pay approach requires data from surveys, which involves an additional effort. On the other hand, reducing or eliminating intangible costs, would not release resources for other uses, such as for production or consumption. Thus, the resulting benefits may not be so interesting.

Recommendations for using the top-down or bottom-up approaches do not address all related problems, so we would 
like to provide further recommendations for use in COI studies that were not considered in previous guidelines. The following bullet points are intended to serve as a supplement to the guidelines for top-down COI estimates:

- Which diseases/injuries and criminal conditions should be included? For the former, this may refer to either the Global Burden of Disease, Injuries, and Risk Factors Study (GBD) (http://www.healthdata.org/gbd/2019) or to the WHO framework (2018); for an underlying overview, see Rehm and colleagues (2017). Both systems have explicit groups and clear rules how new conditions could be included.

- What exposure data should be referred to? For each country, and for many sub regions, exposure data are available, which are regularly updated; for example, Manthey and colleagues (2019) or the WHO Global Information System on Alcohol and Health (2020).

- What morbidity and mortality data should be referred to? For morbidity, many countries have hospital data, but this needs to be checked for each jurisdiction. Similarly, for mortality data, the above-mentioned sources give regular updates.

- Where should risk attributions be obtained? GBD and WHO give regular updates (GBD: Murray and colleagues (2020); WHO-based: Shield and colleagues (2020); see also Sherk and colleagues (2020)). Please note that all these systems are based on continuous exposure estimates; for a discussion, see Rehm and colleagues (2010).

None of the guidelines we identified addressed methodological problems of performing bottom-up COI studies, thus we propose the following recommendations below:

- Costs attributable to alcohol consumption may be calculated as the difference in costs between alcohol drinkers and a comparison group, i.e., as excess costs: for example, Dams and colleagues (2018) and Manthey, Laramée, Parrott, and Rehm (2016).

- As cross-sectional data do not allow for the identification of events causally impacted by alcohol, it is important to account for possibly confounding factors in the analyses, for example tobacco smoking.

- Cost estimates should be corrected for the degree of underreporting of alcohol use; for example, if populations known to be prone to heavy drinking are excluded from the sample. For the degree of underreporting in Europe, see Kilian and colleagues (2020); for a discussion on representativeness of alcohol surveys, see Rehm, Kilian, Rovira, Shield, and Manthey (2020).

- The sample bias is not restricted to the population of drinkers but also affects the comparison group. For instance, if this group is not sampled from the general population but from patient registries (for example, see Miquel and colleagues (2018)), this may attenuate the cost difference which should be clearly labelled and discussed.

Limitations inherent to the bottom-up approach should be explicitly mentioned and discussed. Advantages of bottomup studies, for example to estimate the costs of harm to others than the drinkers, should be explored and exploited (for a review, see Navarro, Doran, and Shakeshaft (2011)).

Before discussing further details of COI studies, we want to lay out limitations of the current systematic review: Firstly, the results of any systematic review are limited by the underlying studies. The identified set of studies are characterized by high heterogeneity and lack of adherence to common methodological standards. This situation made it almost impossible to do the customary formal quality assessment for each study (Higgins \& Green, 2011). Quality assessment would have required a decision on the gold standard, according to which all studies could have been judged. As we found a general lack of compliance with any methodological standard, we decided instead to describe these differences, rather than to quantify them using one guideline (or a set of assumptions as a gold standard). Secondly, some COI studies mandated by governments may never have been published in peer-reviewed literature, and thus were missed in our search strategy. Thirdly, studies in other than standard languages were excluded. Finally, the heterogeneity of the articles did not allow for the more sophisticated statistical procedures.

However, the key results of our study remain unchanged despite the outlined limitations. The current practice of COI studies does not reach its potential because of high heterogeneity and a lack of comparability. The steady increase of new COI studies in different parts of the world requested by governments shows that they could potentially serve as an important part of monitoring alcohol use (Rehm, 2012). However, in their current form, they cannot adequately fulfill this role, as studies are invariably noncomparable over time and jurisdiction. Thus, they are primarily reduced to producing specific estimates, with some epidemiological details. Their full potential could only be realized if a common standard were adopted.

Although guidelines provide suggestions for optimal conditions that cost estimates should meet, these cannot often be attained. Therefore, basic conditions for cost studies should be proposed in order to achieve a certain level of comparability. But how could such a standard be achieved? In this context, it is necessary to differentiate between content-related and technical standards.

Content-related standardization could be achieved, for example, by using established categories of costs (i.e., direct, indirect) and to select relevant cost components that are agreed to be affected by alcohol use, as described in our contribution. If all future studies were to report costs using the same framework, this would increase the chance of missing value imputations and thus enhance study quality. Moreover, heterogeneity in estimating productivity losses should be reduced. For health care, costs are usually estimated by multiplying the number of alcohol-attributable events (e.g., hospitalizations) with the resources (i.e., unit costs) associated with this event. Establishing a comparable standard for estimating productivity losses may reduce heterogeneity in estimating the cost of illness, not only for alcohol use (Mattke, Balakrishnan, Bergamo, \& Newberry, 2007). 
Technical standardization could be achieved by applying easy-to-use software, where different countries only need to input their country-specific data to overwrite defaults. The situation would be similar to other areas of health science, where standardization was achieved by software to facilitate disease modelling (such as DISMOD, which was one of the drivers to standardize the burden of disease calculations (Barendregt, van Oortmarssen, Vos, \& Murray, 2003)); or to estimate the economic effects of policy interventions (WHO OneHealth Tool (World Health Organization, 2012)). Thus, the development of such software could improve the current situation and introduce standardization.

As a result of adopting these standards, heterogeneity in COI studies caused by alcohol use could be reduced and comparability enhanced.

\section{References}

Adams, M., \& Effertz, T. (2010). Die volkswirtschaftlichen Kosten des Alkohol- und Nikotinkonsums. In M. V. Singer, A. Batra, \& K. Mann (Eds.), Alkohol, Tabak und Folgeerkrankungen. Stuttgart: Thieme.

Alberto Vella, V., García-Altes, A., Segura García, L., Ibáñez Martínez, N., \& Colom Farran, J. (2018). Systematic review of guidelines in estimating social costs on drugs. Gaceta Sanitaria, 32(5), 481-487. https://doi.org/10.1016/j.gaceta.2017.10.009

Barendregt, J. J., van Oortmarssen, G. J., Vos, T., \& Murray, C. J. L. (2003). A generic model for the assessment of disease epidemiology: The computational basis of DisMod II. Population Health Metrics, 1(1), 4. https://doi.org/10.1186/1478-7954-1-4

Barkey, P. M. (2009). The Economic Cost of Alcohol Abuse in Montana. Missoula, MT: The University of Montana.

Beale, S., Sanderson, D., Kruger, J., Glanville, J., \& Duffy, S. (2010). The Societal Cost of Alcohol Misuse in Scotland for 2007. Retrieved from: http://drugslibrary.wordpress.stir.ac.uk/files/2017/03/S Galocohol_cost_to_society.pdf

Bohs, R., \& Sayed, B. (2009). The Annual Economic Impact of Alcohol and Drug Use in Florida. Retrieved from: https://www.semanticscholar.org/paper/The-AnnualEconomic-Impact-of-Alcohol-and-Drug-Use-BohsSayed/4c802a87ccc253b465dae6f65956880c6058241f

Byford, S., Torgerson, D. J., \& Raftery, J. (2000). Economic note: cost of illness studies. BMJ, 320(7245), 1335. https://doi.org/10.1136/bmj.320.7245.1335

Chisholm, D., Moro, D., Bertram, M., Pretorius, C., Gmel, G., Shield, K., \& Rehm, J. (2018). Are the "Best Buys" for alcohol control still valid? An update on the comparative cost-effectiveness of alcohol control strategies at the global level. Journal of Studies on Alcohol and Drugs, 79(4), 514-522. https://doi.org/10.15288/jsad.2018.79.514

Collins, D., Lapsley, H., Brochu, S., Easton, B., Gómez, A., Rehm, J., \& Single, E. (2006). International Guidelines for the Estimation of the Avoidable Costs of Substance Abuse. Ottawa: Health Canada.

Dams, J., Buchholz, A., Kraus, L., Reimer, J., Scherbaum, N., Konnopka, A., \& König, H.-H. (2018). Excess costs of alcohol-dependent patients in German psychiatric care compared with matched non-alcohol-dependent individuals from the general population: A secondary analysis of two datasets. BMJ Open, 8(8), e020563. https://doi.org/10.1136/bmjopen-2017-020563

Department of Health Social Services and Public Safety. (2010). Social Costs of Alcohol Misuse in Northern Ireland for 2008/09. Retrieved from: https://www.drugsandalcohol.ie/13337/1/NI_Social_co sts_of_alcohol_misuse_200809.pdf

Drummond, M. (1992). Cost-of-illness studies: a major headache? Pharmacoeconomics, 2(1), 1-4. https://doi.org/10.2165/00019053-199202010-00001

Higgins, J. P. T., \& Green, S. (2011). 21.4 Assessment of study quality and risk of bias. In Cochrane Handbook for Systematic Reviews of Interventions (Vol. 5.1.0): The Cochrane Collaboration.

Hodgson, T. A., \& Meiners, M. R. (1982). Cost-of-illness methodology: A guide to current practices and procedures. The Milbank Memorial Fund Quarterly. Health and Society, 60(3), 429-462. https://doi.org/10.2307/3349801

Ivano Scandurra, R., Garcia-Altes, A., \& Nebot, M. (2011). Social impact of abusive alcohol consumption in Spain: Consumption, cost and policies. Revista Española de Salud Pública, 85(2), 141-147. https://www.mscbs.gob.es/biblioPublic/publicaciones/r ecursos_propios/resp/revista_cdrom/vol85/vol85_2/RS 852C_141.pdf

Jarl, J., Gerdtham, U. G., Ludbrook, A., \& Petrie, D. (2010). On measurement of avoidable and unavoidable cost of alcohol: An application of method for estimating costs due to prior consumption. International Journal of Environmental Research and Public Health, 7(7), 28812895. https://doi.org/10.3390/ijerph7072881

Jones-Lee, M. W. (1992). Paternalistic altruism and the value of statistical life. The Economic Journal, 102(410), 80-90. https://doi.org/10.2307/2234853

Jyani, G., Prinja, S., Ambekar, A., Bahuguna, P., \& Kumar, R. (2019). Health impact and economic burden of alcohol consumption in India. International Journal of Drug Policy, 69, 34-42. https://doi.org/10.1016/j.drugpo.2019.04.005

Kilian, C., Manthey, J., Probst, C., Brunborg, G. S., Bye, E. K., Ekholm, O., . . Rehm, J. (2020). Why is per capita consumption underestimated in alcohol surveys? Results from 39 surveys in 23 European countries. Alcohol and Alcoholism, 55(5), 554-563. https://doi.org/10.1093/alcalc/agaa048

Kim, J., Chung, W., Lee, S., \& Park, C. (2010). Estimating the socioeconomic costs of alcohol drinking among adolescents in Korea. Journal of Preventative Medicine and Public Health, 43(4), 341-351. https://doi.org/10.3961/jpmph.2010.43.4.341

Koopmanschap, M. A., Rutten, F. F., van Ineveld, B. M., \& van Roijen, L. (1995). The friction cost method for measuring indirect costs of disease. Journal of Health Economics, 14(2), 171-189. https://doi.org/10.1016/0167-6296(94)00044-5

Kopp, P., \& Ogrodnik, M. (2017). The social cost of drugs in France in 2010. European Journal of Health Economics, 18(7), 883-892. https://doi.org/10.1007/s10198-016-0835-9 
Lievens, D., Vander Laenen, F., Verhaeghe, N., Putman, K., Pauwels, L., Hardyns, W., \& Annemans, L. (2017). Economic consequences of legal and illegal drugs: The case of social costs in Belgium. The International Journal on Drug Policy, 44, 50-57. https://doi.org/10.1016/j.drugpo.2017.03.005

Mäkelä, K. (2012). Cost-of-alcohol studies as a research programme. Nordic Studies on Alcohol and Drugs, 29(4), 321-343. https://doi.org/10.2478/v10199-0120026-7

Manning, M., Smith, C., \& Mazerolle, P. (2013). The societal costs of alcohol misuse in Australia. Trends and Issues in Crime and Criminal Justice, 1-6.

Manthey, J., Laramée, P., Parrott, S., \& Rehm, J. (2016). Economic burden associated with alcohol dependence in a German primary care sample: A bottom-up study. BMC Public Health, 16(1), 906. https://doi.org/10.1186/s12889-016-3578-8

Manthey, J., Shield, K. D., Rylett, M., Hasan, O. S. M., Probst, C., \& Rehm, J. (2019). Alcohol exposure between 1990 and 2017 and forecasts until 2030: A global modelling study. The Lancet, 393(10190), 24932502. https://doi.org/10.1016/S0140-6736(18)32744-2

Mattke, S., Balakrishnan, A., Bergamo, G., \& Newberry, S. J. (2007). A review of methods to measure health-related productivity loss. American Journal of Managed Care, 13(4), 211-217.

Matzopoulos, R. G., Truen, S., Bowman, B., \& Corrigall, J. (2014). The cost of harmful alcohol use in South Africa. South African Medical Journal, 104(2), 127-132. https://doi.org/10.7196/samj.7644

Miller, T. R., Nygaard, P., Gaidus, A., Grube, J. W., Ponicki, W. R., Lawrence, B. A., \& Gruenewald, P. J. (2017). Heterogeneous costs of alcohol and drug problems across cities and counties in California. Alcoholism: Clinical \& Experimental Research, 41(4), 758-768. https://doi.org/10.1111/acer.13337

Miquel, L., Rehm, J., Shield, K. D., Vela, E., Bustins, M., Segura, L., . . Gual, A. (2018). Alcohol, tobacco and health care costs: A population-wide cohort study $(n=$ 606947 patients) of current drinkers based on medical and administrative health records from Catalonia. European Journal of Public Health, 28(4), 674-680. https://doi.org/10.1093/eurpub/ckx236

Moher, D., Liberati, A., Tetzlaff, J., \& Altman, D. G. (2009). Preferred reporting items for systematic reviews and meta-analyses: The PRISMA statement. PLoS Medicine, 6(7),

e1000097. https://doi.org/10.1371/journal.pmed.1000097

Møller, L., \& Matic, S. (2010). Best practice in estimating the costs of alcohol - Recommendations for future studies. In L. Møller \& S. Matic (Eds.). Retrieved from http://www.euro.who.int/_data/assets/pdf_file/0009/11 2896/E93197.pdf

Murray, C. J., Aravkin, A. Y., Zheng, P., Abbafati, C., Abbas, K. M., Abbasi-Kangevari, M., . . . Lim, S. S. (2020). Global burden of 87 risk factors in 204 countries and territories, 1990-2019: A systematic analysis for the Global Burden of Disease Study 2019. The Lancet, 396(10258), 1223-1249. https://doi.org/10.1016/S01406736(20)30752-2
Murray, C. J., Ezzati, M., Lopez, A. D., Rodgers, A., \& Vander Hoorn, S. (2003). Comparative quantification of health risks conceptual framework and methodological issues. Population Health Metrics, 1(1), 1. https://doi.org/10.1186/1478-7954-1-1

Murray, C. J., Govindaraj, R., \& Musgrove, P. (1994). National health expenditures: A global analysis. Bulletin of the World Health Organization, 72(4), 623-637.

Navarro, H. J., Doran, C. M., \& Shakeshaft, A. P. (2011). Measuring costs of alcohol harm to others: A review of the literature. Drug and Alcohol Dependence, 114(2), 87-99. https://doi.org/10.1016/j.drugalcdep.2010.11.009

Paileeklee, S., Kanato, M., Kaenmanee, S., \& McGhee, S. M. (2010). Alcohol Drinking Behaviour and Economic Cost Incurred by Users in Khon Kaen. Journal of the Medical Association of Thailand [Chotmaihet thangphaet], Suppl 3, S38-S44.

Quinet, E. (2014). L'évaluation Socioéconomique des Investissements Publics: PSE Working Papers halshs01059484, HAL.

Ranaweera, S., Amarasinghe, H., Chandraratne, N., Thavorncharoensap, M., Ranasinghe, T., Karunaratna, S., . . De Silva, A. (2018). Economic costs of alcohol use in Sri Lanka. PLoS One, 13(6), e0198640. https://doi.org/10.1371/journal.pone.0198640

Rehm, J. (2012). Article Commentary: Cost of illness studies for alcohol consumption - Why are they still in demand? Nordic Studies on Alcohol and Drugs, 29(4), 345-348. https://doi.org/10.2478/v10199-012-0027-6

Rehm, J., Baliunas, D., Brochu, S., Fischer, B., Gnam, W., Patra, J., . . . Taylor, B. (2006). The Costs of Substance Abuse in Canada 2002. Ottawa: Canada Centre for Substance Abuse.

Rehm, J., Gmel Sr, G. E., Gmel, G., Hasan, O. S. M., Imtiaz, S., Popova, S., . . Shuper, P. A. (2017). The relationship between different dimensions of alcohol use and the burden of disease - an update. Addiction, 112(6), 9681001. https://doi.org/10.1111/add.13757

Rehm, J., \& Imtiaz, S. (2016). A narrative review of alcohol consumption as a risk factor for global burden of disease. Substance Abuse Treatment, Prevention, and Policy, 11. https://doi.org/10.1186/s13011-016-0081-2

Rehm, J., Kehoe, T., Gmel, G., Stinson, F., Grant, B., \& Gmel, G. (2010). Statistical modeling of volume of alcohol exposure for epidemiological studies of population health: The US example. Population Health Metrics, 8(1), 3. https://doi.org/10.1186/1478-7954-8-3

Rehm, J., Kilian, C., Rovira, P., Shield, K. D., \& Manthey, J. (2020). The elusiveness of representativeness in general population surveys for alcohol. Drug and Alcohol Review, $\quad n / a(\mathrm{n} / \mathrm{a})$. https://doi.org/10.1111/dar.13148

Rehm, J., Mathers, C., Popova, S., Thavorncharoensap, M., Teerawattananon, Y., \& Patra, J. (2009). Global burden of disease and injury and economic cost attributable to alcohol use and alcohol-use disorders. Lancet, 373, 2223-2233. https://doi.org/10.1016/S0140-6736(09)60746-7

Rehm, J., Shield, K. D., Gmel, G., Rehm, M. X., \& Frick, U. (2013). Modeling the impact of alcohol dependence on mortality burden and the effect of available treatment 
interventions in the European Union. European Neuropsychopharmacology, 23(2), 89-97. https://doi.org/10.1016/j.euroneuro.2012.08.001

Rehm, J., Taylor, B., Patra, J., \& Gmel, G. (2006). Avoidable burden of disease: conceptual and methodological issues in substance abuse epidemiology. International Journal of Methods in Psychiatric Research, 15(4), 181-191. https://doi.org/10.1002/mpr.199

Rice, D. P. (1966). Estimating the cost of illness. Health Economics Series, No. 6. DHEW Publication No. (PHS) 947-6. Rockville, MD: US Department of Health, Education, and Welfare.

Rice, D. P. (1967). Estimating the cost of illness. American Journal of Public Health and the Nation's Health, 57(3), 424-440. https://doi.org/10.2105/ajph.57.3.424

Rice, D. P., Kelman, S., \& Miller, L. S. (1991). Estimates of economic costs of alcohol and drug abuse and mental illness, 1985 and 1988. Public health reports (Washington, D.C: 1974), 106(3), 280-292.

Rice, D. P., Kelman, S., Miller, L. S., \& Dunmeyer, S. (1990). The economic cost of alcohol and drug abuse in mental illness: 1985. Retrieved from: https://www.ojp.gov/library/abstracts/economic-costsalcohol-and-drug-abuse-and-mental-illness-1985

Saar, I. (2009). The social costs of alcohol misuse in Estonia. European Addiction Research, 15(1), 56-62. https://doi.org/10.1159/000173010

Sherk, A., Stockwell, T., Rehm, J., Dorocicz, J., Shield, K. D., \& Churchill, S. (2020). The international model of alcohol harms and policies: A new method for estimating alcohol health harms with application to alcohol-attributable mortality in Canada. Journal of Studies on Alcohol and Drugs, 81(3), 339-351. https://doi.org/10.15288/jsad.2020.81.339

Shield, K., Manthey, J., Rylett, M., Probst, C., Wettlaufer, A., Parry, C. D. H., \& Rehm, J. (2020). National, regional, and global burdens of disease from 2000 to 2016 attributable to alcohol use: A comparative risk assessment study. The Lancet Public Health, 5(1), e51e61. https://doi.org/10.1016/S2468-2667(19)30231-2

Shield, K. D., Soerjomataram, I., \& Rehm, J. (2016). Alcohol Use and Breast Cancer: A Critical Review. Alcoholism: Clinical and Experimental Research, 40(6), 1166-1181. https://doi.org/10.1111/acer.13071

Single, E., Collins, D., Easton, B., Harwood, H., Lapsley, H., Kopp, P., \& Wilson, E. (2003). International guidelines for estimating the costs of substance abuse (2nd ed.). Geneva: Wold Health Organization.

Single, E., Collins, D., Easton, B., Harwood, H., Lapsley, H., \& Maynard, A. (1996). International Guidelines for Estimating the Costs of Substance Abuse. Ottawa, Canada: Canadian Centre on Substance Abuse.

Stanaway, J. D., Afshin, A., Gakidou, E., Lim, S. S., Abate, D., Abate, K. H., . . . Murray, C. J. L. (2018). Global, regional, and national comparative risk assessment of 84 behavioural, environmental and occupational, and metabolic risks or clusters of risks for 195 countries and territories, 1990-2017: A systematic analysis for the Global Burden of Disease Study 2017. The Lancet, 392(10159), 1923-1994. https://doi.org/10.1016/S01406736(18)32225-6
Thavorncharoensap, M., Teerawattananon, Y., Yothasamut, J., Lertpitakpong, C., \& Chaikledkaew, U. (2009). The economic impact of alcohol consumption: a systematic review. Substance Abuse Treatment, Prevention, and Policy, 4, 20. https://doi.org/10.1186/1747-597x-4-20

Thavorncharoensap, M., Teerawattananon, Y., Yothasamut, J., Lertpitakpong, C., Thitiboonsuwan, K., Neramitpitagkul, P., \& Chaikledkaew, U. (2010). The economic costs of alcohol consumption in Thailand, 2006. BMC Public Health, 10(1), 323. https://doi.org/10.1186/1471-2458-10-323

Verhaeghe, N., Lievens, D., Annemans, L., Vander Laenen, F., \& Putman, K. (2017). The health-related social costs of alcohol in Belgium. BMC Public Health, 17(1), 958. https://doi.org/10.1186/s12889-017-4974-4

Wickizer, T. M. (2013). State-level estimates of the economic costs of alcohol and drug abuse. Journal of Health Care Finance, 39(3), 71-84.

World Health Organization. (2010). Global strategy to reduce the harmful use of alcohol. Retrieved from https://www.who.int/substance_abuse/alcstratenglishfin al.pdf

World Health Organization. (2018). Global status report on alcohol and health 2018. Retrieved from https://apps.who.int/iris/bitstream/handle/10665/27460 3/9789241565639-eng.pdf

World Health Organization. (2020). Global Information System on Alcohol and Health. Retrieved from http://www.who.int/gho/alcohol/en/index.html 